\title{
GESTÃO EDUCACIONAL INOVADORA: O PROFESSOR NA CULTURA DIGITAL
}

http://dx.doi.org/10.5902/2318133817610

\author{
Edenise do Amaral Favarin \\ Universidade Federal de Santa Maria, Brasil.
}

Adriana Moreira da Rocha

Universidade Federal de Santa Maria, Brasil.

\section{Resumo}

Este artigo é um recorte do trabalho monográfico e tem como objetivo geral compreender a ênfase dada à formação do professor nas políticas públicas de formação de professores e no projeto político-pedagógico do curso de licenciatura em Pedagogia diurno presencial da Universidade Federal de Santa Maria. O processo metodológico envolveu a pesquisa bibliográfica e a análise de documentos legais. O PPP do curso está em consonância com os documentos legais analisados. Contudo, inferimos que pelo fato do referido PPP considerar minimamente a cultura digital como referência curricular na formação do futuro professor, demonstra distanciamento da referência cultural das novas gerações, aspecto importante destacado também nas DCN para o curso de Pedagogia.

Palavras-chave: gestão educacional, políticas públicas de formação de professores, projeto político pedagógico.

\section{INNOVATIVE EDUCATIONAL MANAGEMENT: THE PEDAGOGUE/MANAGER IN THE DIGITAL CULTURE}

\begin{abstract}
This paper is part of a larger study and it aims at understanding the emphasis given to the pedagogue/manager education in teachers' education policies and the political pedagogical project of the Pedagogy major at the Federal University of Santa Maria. The methodological process consisted of bibliographic research and official documents analysis. The PPP is in accordance with the official documents that were analyzed. However, the PPP slightly considers the digital culture as a curricular reference for the education of the pre service pedagogue/manager. We infer that it shows a detachment from the culture in which the new generation is immersed, which is an important aspect that is also highlighted in the Pedagogy major national curricular guidelines.

Key-words: educational management, teachers' education policies, political pedagogical project.
\end{abstract}


$\mathrm{O}$ s estudantes do século 21 já nasceram na cultura digital e por isso são reconhecidos como nativos digitais ${ }^{1}$. Conforme Marc Prensky (2001), estes são os aprendizes do novo milênio e, levando em conta a sua inserção na sociedade da informação e do conhecimento, o desafio de ser professor/gestor aumenta, tendo em vista que os estudantes de hoje não tem mais o perfil de antes, pois transitam com desenvoltura pelas mídias, dominando as $\mathrm{TDIC}^{2}$ e os espaços virtuais.

O conceito de cultura digital ainda não está consolidado, contudo, aproxima-se de conceitos como sociedade da informação, cibercultura, revolução digital e era digital, os quais expressam que as relações humanas são caracterizadas pela mediação das TDIC. Em concordância com os pressupostos de Lévy (1999), as TDIC não causam impactos na sociedade, visto que elas emergiram a partir da necessidade humana e não se encontram dissociadas da cultura e da sociedade, pois se fomos analisar a história ela aponta que 0 homem, além de desenvolver uma relação de medo, dominação, referente à técnica, passou a criar as técnicas e objetos com a finalidade de auxiliá-los em seus afazeres cotidianos.

Considerando esta concepção, entendemos que as técnicas, as tecnologias condicionam a cultura e a sociedade pelo fato de abrir possibilidades e de promover a integração de contextos culturais diversificados, que sem a sua presença não poderiam ser pensadas. Nessa direção, a inteligência coletiva na cultura digital ganha evidência, pois pode ser definida como um tipo de inteligência compartilhada que emerge a partir da colaboração dos indivíduos, considerando a heterogeneidade existente - proposta esta que pode ser levada para os contextos formativos iniciais.

Para mediar os processos formativos de ensino e aprendizagem, torna-se necessário mobilizar mais do que as práticas de gestão tradicionais, típicas de uma geração de professores que, "encapsulada em si mesma, não enxerga as possibilidades de se aproximar de uma outra, que apesar de estar tão perto, apresenta-se tão distante" (Freitas, 2009, p. 1).

Os nativos digitais invadiram os espaços educativos. Ensinar essa nova geração é um desafio, especialmente para os professores, pois estes precisam avançar em relação a aula expositiva e deixar que os estudantes aprendam a partir de suas próprias experiências. Assim,

é interessante analisar a relação entre inovação educativa e profissão docente. Entendida como pesquisa educativa na prática, a inovação requer novas e velhas concepções pedagógicas e uma nova cultura profissional forjada nos valores da colaboração e do progresso social, considerado como transformação educativa e social. (Imbernón, 2010, p. 20)

\footnotetext{
1 Termo designativo para quem nasceu e está crescendo com as tecnologias digitais de informação e comunicação - TDIC - presentes em sua vida cotidiana.

$2 \mathrm{O}$ termo TIC remete as tecnologias da informação e comunicação. Consistem em um conjunto de recursos tecnológicos tanto analógicos quanto digitais, que ao integrar-se proporcionam a automação e a comunicação dos processos de negócios, da pesquisa científica e dos processos de ensinar e aprender, por meio de hardware, software e telecomunicações. Embora o termo TIC seja utilizado como aporte teórico de pesquisas, inclusive nos referenciais teóricos utilizados por nós, neste estudo, optamos em utilizar o conceito de Tecnologia Digital da Informação e da Comunicação, no qual se insere a palavra digital. Todo sistema digital tem como base o sistema de numeração binário. Aparelhos como desktop, notebook, netbook, tablet, a web, os telefones celulares mais sofisticados, as câmeras digitais, o televisor digital e as demais tecnologias constituem as TDIC.
} 
Partimos do pressuposto de que formar em uma perspectiva humano-tecnológica de educação, frente aos desafios da gestão e da cultura digital, fornece ao futuro professor condições de ir além da técnica e refletir sobre a sua atuação num determinado contexto sociocultural. No contexto do século 21 a TDIC tornou-se uma ferramenta potencializadora dos processos de ensino e aprendizagem, a qual os estudantes a exploram em busca de informações que podem complementar as explicações aprendidas em aula e constituir-se em uma ferramenta aliada do professor durante o processo da construção do conhecimento.

Por isso, a importância do professor repensar a sua prática e compreender as teorias que embasam as tomadas de decisões diante dos desafios proporcionados pela cultura digital. Nesse contexto,

a formação assume um papel que transcende o ensino que pretende uma mera atualização científica, pedagógica e didática e se transforma na possibilidade de criar espaços de participação, reflexão e formação para que as pessoas aprendam e se adaptem para poder conviver com a mudança e a incerteza. (Imbernón, 2010, p. 15)

Trata-se de conduzir os estudantes no e pelo trabalho com as TDIC, para que não se atribua as mesmas o estatuto de meros instrumentos para quaisquer finalidades (Barreto, 2003), utilizando-se para uma educação transformadora, considerando a inserção dos nativos digitais em espaços educativos presencias e virtuais.

Entendemos que, a formação docente é desafiada a enfrentar uma nova esfera pedagógica: a virtual, que é representada pela integração das TDIC na educação, a qual os professores não se sentem preparados. Dessa maneira, surge a necessidade de uma formação pedagógica com a integração das tecnologias digitais, resultando em novas relações pedagógicas no exercício da docência, pois os professores continuam com o modelo pedagógico tradicional, mas, introduzem recursos multimídias em seu planejamento de ensino, sem, no entanto, romper com o modelo estabelecido.

Para isso, uma formação reflexiva e a realização de práticas de gestão inovadoras tornam-se o ponto chave para o enfrentamento dos desafios da cultura digital, uma vez que $o$ trabalho docente envolve $o$ ensino $e$ as relações entre sujeitos com 0 conhecimento.

Nessa direção, buscamos compreender a ênfase dada à formação do professor nas políticas públicas de formação de professores e no projeto político-pedagógico do curso de licenciatura em Pedagogia diurno presencial da Universidade Federal de Santa Maria. O processo metodológico envolveu a pesquisa bibliográfica baseada nas diretrizes para a leitura, análise e interpretação de textos proposta por Severino (2007) e a análise de documentos legais fundamentada na perspectiva de Chizzotti (2010). A definição conceitual foi construída a partir dos conceitos pedagogia, gestão educacional, projeto político pedagógico, formação de professores e cultura digital.

\section{O professor no século 21: desafios da cultura digital}

Diante dos desafios à docência, promovidos pela cultura digital, cabe a nós questionarmos: para onde estamos caminhando nos processos de ensinar e aprender? $\mathrm{Na}$ tentativa de responder a estes desafios, Moran (2000) diz que a maioria das formas de 
ensinar não se justifica mais diante do cenário educativo constituído pela integração das TDIC em que perdemos tempo demais, abstraímos muito pouco do que aprendemos e constantemente nos desmotivamos. A convicção de que as aulas tradicionais estão ultrapassadas, isto já sabemos e defendemos, mas o maior desafio é compreender como ensinar e aprender na cultura digital?

Sabemos que a educação é o caminho fundamental para transformar a sociedade e, em outras épocas, havia a expectativa de que as tecnologias forneceriam a solução rápida para os problemas de ensino. É verdadeiro afirmar que as TDIC possibilitam a ampliação do conceito de aula, de espaço-tempo, de comunicação audiovisual, estabelecendo "pontes novas entre o presencial e o virtual, entre o estar juntos e o estarmos conectados a distância" (Moran, 2000, p. 120).

No entanto, se o ensinar dependesse unicamente das TDIC a solução para os problemas da educação já estariam cessados, no entanto, infelizmente elas não resolvem as questões que servem como pano de fundo, pois "ensinar e aprender são desafios maiores que enfrentamos em todas as épocas e particularmente agora em que estamos pressionados pela transição do modelo de gestão industrial para o da informação e do conhecimento" (Moran, 2000, p. 12).

Ao refletir sobre a formação de professores, observamos que se tem, em geral, uma maioria de professores da área da Educação que foi formado para ser ensinante, para transmitir conteúdos, disciplinas. Em seu processo formativo receberam uma grande carga horária de conteúdos de áreas e metodologias de ensino, ao invés da ênfase ao aprendizado de teorias pedagógicas e educativas.

Um dos maiores desafios que encontramos é proporcionar aos estudantes uma educação de qualidade que prime pela integração das dimensionalidades humanas, em busca da diminuição das relações interpessoais permeadas pelo autoritarismo. As mudanças no cenário educativo também dependem de um modelo de gestão em que os gestores estejam mais abertos e dispostos a compreender todas as dimensões que estão envolvidas no processo pedagógico, além da dimensão administrativa, voltada ao lucro, ou seja, "que seres os professores inovadores, que equilibrem o gerenciamento empresarial, tecnológico e o humano, contribuindo para que haja um ambiente de maior inovação, intercâmbio e comunicação" (Moran, 2000, p. 17).

As TDIC podem auxiliar naquilo que já fazemos ou desejamos, pois, se somos professores abertos e flexíveis, elas podem ampliar a comunicação, facilitando a mudança e a possibilidade de propostas inovadoras e se somos mais resistentes, a tendência é utilizá-las como formas de controle.

Propomos aos professores/gestores abertos e flexíveis, imersos na cultura digital, que atuem como orientador/mediador de aprendizagem. De acordo a sua concepção de Moran (2000), o professor pode se tornar um orientador/gestor do processo de aprendizagem, integrando equilibradamente as dimensões intelectual, emocional e a gerencial. $\mathrm{O}$ autor concebe o educador como um pesquisador que aprende a partir de sua prática e ensina mediante aquilo que aprende: "realiza-se aprendendo-pesquisandoensinando-aprendendo" (Moran, 2000, p. 30).

Acreditamos que as TDIC oferecem aos professores um leque de opções metodológicas, de possibilidades de estabelecer comunicação com os estudantes, de introduzir um tema e de trabalhar presencial ou virtualmente, inclusive avaliá-los. Cada 
professor poderá recriar formas de integração das TDIC a outros procedimentos metodológicos, o que não significa a elaboração de fórmulas, de receitas prontas que podem ser aplicáveis a todos os contextos educativos. É importante que cada um encontre uma maneira própria de se comunicar, ensinar e aprender, desenvolver atividades e formas alternativas de avaliação.

Pensar sob essa perspectiva, conduz a um tipo de gestão que implica em mudanças no ensino presencial com TDIC, no entanto, não significa que haverá o abandono total da organização tradicional dos cursos presenciais. A ideia é utilizá-las como um recurso didático-pedagógico que medie os processos de ensino e aprendizagem de modo participativo, pois há momentos em que é necessário o encontro físico e há outros em que aprendemos mais estando cada um em seu espaço habitual, mas conectados com os demais colegas e professores, propiciando a educação permanente.

Com base em Moran (2000), se temos dificuldades no ensino presencial, não resolveremos com o virtual, no entanto, é importante que se tenha um equilíbrio, uma vez que há diferenças entre estas modalidades: "estar juntos fisicamente é importante em determinados momentos fortes, conhecer-nos criar elos, confiança, afeto. Conectados, podemos realizar trocas mais rápidas, cômodas e práticas" (Moran, 2000, p. 58). Educar ou realizar processos de gestão com novas TDIC será uma revolução se mudarmos simultaneamente os paradigmas tradicionais de ensino que mantém a distância entre professores e estudantes.

O professor do século 21 é um profissional que atua imerso na cultura digital e com a mediação sociocultural das TDIC necessita reconfigurar os percursos individuais referentes aos saberes docentes. Isto não implica em utilizar as TDIC a qualquer custo, e instituí-la verticalmente nos processos formativos iniciais, em substituir o ensino presencial pelo ensino à distância, nem mesmo migrar da forma escrita e da comunicação oral para a multimídia, mas sim "acompanhar consciente e deliberadamente uma mudança de civilização que questiona profundamente as formas institucionais, as mentalidades e a cultura dos sistemas educacionais tradicionais e sobretudo os papéis de professor e de aluno" (Moran, 2000, p. 174).

Diante desse quadro, a educação está passando por um período de adaptação, no que se refere à presença de equipamentos tecnológicos em sala de aula que, dependendo de como o professor a contempla, podem ser tornar os vilões dos processos de ensino e aprendizagem ou um recurso que auxilie na mediação pedagógica, com o intuito de integrar a sala de aula com o ciberespaço, constituindo de modo efetivo o que tem sido o principal meio de comunicação com os estudantes - nativos digitais.

Inovar o ensino, a partir da integração das TDIC, é uma das atribuições do professor que visa a modificar qualitativamente os processos de aprendizagem na cultura digital, visto que

a principal função do professor não pode mais ser uma difusão dos conhecimentos, que agora é feita de forma mais eficaz por outros meios. Sua competência deve deslocar-se no sentido de incentivar a aprendizagem e o pensamento. O professor torna-se um animador da inteligência coletiva dos grupos que estão a seu encargo. Sua atividade será centrada no acompanhamento e na gestão das aprendizagens: o 
incitamento à troca dos saberes, a mediação relacional e simbólica, a pilotagem personalizada dos percursos de aprendizagem, etc. (Moran, 2000, p. 173)

Mais do que isso, é necessário encontrar um novo estilo de pedagogia que favoreça, simultaneamente, as aprendizagens personalizadas e as que ocorrem coletivamente em rede. De nada adianta inserir as TDIC na educação e durante a formação sem alterar os mecanismos de validar as aprendizagens obtidas e nessa direção. O professor do século 21 necessita se reinventar, tornando-se um animador da inteligência coletiva, proporcionando aos seus estudantes acesso ao conhecimento a partir de um ensino mais aberto, à distância, e da exploração de novas técnicas que incluem as hipermídias, as redes sociais de comunicação e as tecnologias intelectuais da própria cibercultura.

\section{Gestão educacional inovadora}

Contemporaneamente, formação, gestão e cultura digital deveriam ser contemplados como três elementos indissociáveis nos contextos formativos iniciais, pois o sistema educativo é o setor que sofre maior pressão ocasionada pelas mudanças ocorridas na sociedade.

Percebemos que os estudantes de hoje não têm mais vida social, mas sim uma rede social em que divulgam momentos particulares de sua vida, compartilham ideias, curtem opiniões e têm acesso as mais variadas informações de seu interesse. Conforme Ferreira (2007), isso exige dos professores o desenvolvimento de habilidades cognitivas, comportamentais, rapidez de respostas e criatividade frente às situações desconhecidas, fazendo uso de uma comunicação clara e precisa e da interpretação e uso de diferentes formas de linguagem.

É correto afirmar que a avalanche tecnológica possibilitou mudanças aceleradas que afetaram os processos educativos, alterando hábitos e tradições que outrora pareciam estáveis. Esta nova realidade exige qualificações cada vez mais elevadas para atender às necessidades educacionais da população, pois, de acordo com Ferreira (2007), as tecnologias avançaram mais rapidamente do que a informação, já que, nessa direção, "é necessário evitar certo deslumbramento que tem levado ao uso indiscriminado da tecnologia em suas potencialidades técnicas, em detrimento de suas virtudes científicas, culturais e pedagógicas" (p. 23).

Uma das possíveis formas de superar a utilização indiscriminada da TDIC tem a ver com as formas de realizar os processos de gestão referentes à mediação dos processos de ensino e aprendizagem. Cabe definirmos o que significa o termo gestão:

Provém do verbo latino gero, gessi, gestum, gerere e significa: levar sobre si, carregar, chamar a si, executar, exercer, gerar. Trata-se de algo que implica o sujeito. Isto pode ser visto em um dos substantivos derivados deste verbo. Trata-se de gestatio, ou seja, gestação. É o ato pelo qual se traz, em si e dentro de si, algo novo, diferente: um novo ente. Da mesma raiz provêm os termos genitora, genitor, gérmen. Neste sentido, a gestão é, por analogia, uma geração similar àquela pela qual a mulher se faz mãe ao dar à luz a uma pessoa. (Cunha, 2002, p. 164)

Podemos vislumbrar que a gestão implica em um processo que envolve um ou mais interlocutores, com os quais se dialoga em prol da busca de respostas para as situações 
emergentes. Nessa perspectiva, a "gestão implica o diálogo como forma superior de encontro de pessoas e solução de conflitos" (Cunha, 2002, p. 165) e a esta compete o compromisso de possibilitar uma formação que atenda às necessidades oriundas da cultura digital, a partir do diálogo de imigrantes digitais com os estudantes nativos digitais.

Barroso (2007) nos diz que em discursos políticos alusivos a educação, os ministros substituíram o termo reforma por inovação que "destruiu a sua dinâmica crítica e criadora, transformando-a numa espécie de produto descartável (usa-se e deita-se fora) a sabor das circunstâncias e das modas de cada momento" (p. 118). Esta substituição, nada mais é como uma espécie de inovação mascarada, pois geralmente as mudanças inovadoras implementadas são desprovidas de uma gestão integrada, promovendo práticas desumanizadoras.

O mito das reformas e a inovação, que marcaram as políticas educativas, produziram um certo desencantamento na década de 1990:

Ao entusiasmo redentor que rodeou a maior parte das mudanças sucessivamente tentadas nos mais diversos campos (currículo, métodos de ensino, tecnologias educativas, gestão, formação, organização, etc.), sucedeu-se, pelos seus sucessivos falhanços, um cocktail de sentimentos que vão da frustração ao desespero, da culpa à evasão, do desencanto à diferença. (Barroso, 2007, p. 124)

Não cabe fazer um detalhamento das fragilidades que se sucederam, todavia, merece destaque o acúmulo de promessas feitas que não foram cumpridas, pois diante disto "questionaram práticas que não substituíram, criaram incertezas que não souberam gerir e causaram problemas que não resolveram" (Barroso, 2007, p. 125). Em nossa sociedade, os políticos já não querem mais reformas e os professores desconfiam das mudanças e, por essa razão, torna-se difícil obter o entusiasmo, o ao profissionalismo, a gestão participativa da parte dos docentes.

Diante disso, podemos afirmar que "a nova era requer um profissional da educação diferente" (Imbernón, 2010, p. 12) que promova inovações no contexto educativo em que atua, enfatizando a educação para a vida, na tentativa de superar os enfoques burocráticos, aproximando-se de uma educação mais dialógica e estabelecendo relações entre todos os sujeitos envolvidos nas instituições educativas. Para que isso ocorra, é necessário que a educação democrática adentre as instituições educativas, bem como também haja uma verdadeira reestruturação destes espaços.

Entendemos que outro desafio da educação do século 21 é compreender que os processos de ensino e aprendizagem não se reduzem à transmissão de conhecimento acadêmico e nem tão pouco a transformação dos conhecimentos prévios dos estudantes em um conhecimento oriundo da academia, mas envolve outras funções como a motivação, a luta contra as segregações, pela participação e engajamento da comunidade por uma educação melhor. Implica na possibilidade da criação de espaços participativos, reflexivos e formativos para que as pessoas aprendam a conviver com a imprevisibilidade e a incerteza - inovar (Imbernón, 2010).

A inovação não significa a ruptura total de antigas concepções pedagógicas, mas "requer novas e velhas concepções pedagógicas e uma nova cultura profissional forjada nos valores da colaboração e do progresso social, considerado como transformação educativa e social" (Imbernón, 2010, p. 20). Os processos de inovação não acontecem de 
uma hora para outra, no entanto, adentram-se lentamente no âmbito educativo; não pode ser entendida como um novo conceito de profissionalização docente que rompe com as inércias e práticas do passado. Na perspectiva inovadora, o educador não consiste em um técnico que apenas implementa as inovações prescritas, mas em um profissional que participa de modo ativo e crítico em prol desse processo, tornando o seu contexto de atuação em um espaço dinâmico, dialógico e flexível.

Por isto, mediante Ferreira (2008), é relevante ter a compreensão de que cada um transforma a si mesmo, se modifica, na medida em que transforma e modifica todo o conjunto de relações que são estabelecidas. Nessa direção, passamos a abordar a auto(trans)formação do sujeito, com base em Paulo Freire, pois, para o autor, o sujeito está em um processo constante formativo e transformativo, considerando a perspectiva da formação permanente e a ideia de que consciente da condição de oprimido, o sujeito passa a desenvolver estratégias de libertação frente à realidade opressora, na busca de romper com as amarras que o aprisionam frente a uma sociedade segregadora e repleta de injustiças.

Ao se reinventar como autor de sua própria história, este tem a possibilidade de assumir um posicionamento diante da sociedade que faz parte, em prol da (trans)formação da realidade e da própria auto(trans)formação, libertando-se da condição de um ser domesticado e submisso.

Tornar-se sujeito da história e da própria história só é possível com a libertação dos sujeitos e uma das condições para que a auto(trans)formação ocorra é não os alienar ou os manter alienados, pois a "libertação autêntica, que é a humanização em processo, não é uma coisa que se deposita nos homens. Não é uma palavra a mais, ser, mitificante. É práxis, que implica na ação e na reflexão dos homens seres no mundo para transformá-lo" (Freire, 1983, p. 77).

Entendemos que toda a formação e os modos de fazer gestão são determinados por uma leitura de mundo que os conduz, e que o homem não se reduz somente a um ser cognoscente, mas um ser que é capaz de estar, pensar, agir, sentir no e com o mundo, pois é um sujeito do conhecimento, de vida e de ações, pois

é através da sua ação, com a sua existência - que é práxis - que é capaz de superar sua própria subjetividade e de conhecer a realidade na sua totalidade. Por isso, a vida do ser humano está na construção de sua própria vida na relação dialética como o mundo em que vive. (Ferreira, 2008, p. 55)

Quando se refere à formação e gestão, o conceito de práxis necessita ser repensado, visto que a realidade humana se desenvolve de maneira oposta. Em sua essência, a práxis "é a revelação do segredo do homem como ser ontocriativo, como ser que cria a realidade (humano social) e que, portanto, compreende a realidade (humana e não humana), a realidade na sua totalidade" (Ferreira, 2008, p. 56).

Então, a práxis do ser humano não pode ser uma atividade prática em oposição à teoria, pois incide na determinação da existência humana como preparação da realidade, uma atividade humana consciente que cria a realidade enquanto se recria como ser humano dialeticamente, em espiral, o que torna cada vez mais humano porque cada vez se constitui intérprete e criador de sua realidade. 
Mesmo que os sujeitos encontre-se em uma condição de alienação, o necessário é que "o estudante mantenha vivo em si o gosto da rebeldia que, aguçando sua curiosidade e estimulando sua capacidade de arriscar-se, de aventurar-se, de certa forma o "imuniza" contra o poder apassivador do "bancarismo" (Freire, 2014, p. 27). Essa é uma das características humanas, as quais mostram que somos capazes de ir além de nossos condicionantes.

O que consideramos fundamental para a concepção de formação do ser humano, do professor é a própria práxis como possibilidade de compreensão da realidade, considerando a teoria e a prática como polos complementares e indissociáveis. Nessa direção, Ferreira (2008) sugere a existência da gestão do conhecimento que se compromete com os valores humanos, os quais a humanidade tem direito. A gestão do conhecimento é entendida como

tomada de decisões, organização, e desenvolvimento do pensamento relacional que reflete fidedignamente o movimento real das transformações que se passam no exterior, físico e social com todas as contradições e da produção do conhecimento que se opera no movimento do pensamento. (Ferreira, 2008, p. 71)

Na perspectiva da formação humana, os saberes podem ser contemplados a partir da própria realidade e o ser humano é colocado no centro dos acontecimentos, o que nos torna responsáveis pelo outro que pode ser um ser humano, uma comunidade, um objeto, um patrimônio, etc., incidindo em uma gestão que transcenda a ótica antropocêntrica e individualista e promovendo uma ação auto(trans)formadora das circunstâncias que obstaculizam a verdadeira realização humana.

\section{Políticas públicas de formação de professores e PPP do curso de Pedagogia}

Neste estudo realizamos a análise documental fundamentada em três resoluções: CNE/CP 1, de 18 de Fevereiro de 2002, que institui diretrizes curriculares nacionais para a formação de professores da educação básica, em nível superior, curso de licenciatura, de graduação plena; CNE/CP n. 1, 15 de maio de 2006, que institui diretrizes curriculares nacionais para o curso de graduação em Pedagogia, licenciatura e a n. 4, de 13 de julho de 2010, que institui diretrizes curriculares nacionais gerais para a educação básica.

Nosso propósito é compreender, a partir da análise documental, qual a ênfase dada à formação do professor nas políticas públicas de formação de professores? Esta questão emerge porque novos cenários se reconfiguram, pelo fato da sociedade passar por constantes modificações em ritmo acelerado devido a vários fatores, dentre eles os avanços tecnológicos. A formação de professores necessita ser reconfigurada, proporcionando ao futuro professor maior versatilidade no que se refere ao domínio dos conhecimentos.

A formação docente deve transcender o nível de transmissão de conteúdos prontos (Freire, 2014), receitas prontas a serem aplicadas a todas as turmas, mas desenvolver a capacidade reflexiva e exploratória dos estudantes em prol da reconstrução do conhecimento. Com a integração das TDIC como um recurso didático-pedagógico, os conteúdos podem ser abordados de uma forma que torne a busca pelo saber mais atraente e acessível, através da educação libertadora, que "servindo à libertação, se funda na criatividade e estimula a reflexão e a ação verdadeiras dos homens sobre a 
realidade, responde à sua vocação, como seres que não podem autenticar-se fora da busca e da transformação criadora" (Freire, 2014, p. 83).

Com base na tese de Schneider (2007), a década de 1990 representou um marco na educação brasileira, pois foi considerada como o período das reformas educacionais e da grande afluência de pareceres, diretrizes, parâmetros curriculares consignados pelo Ministério da Educação e Cultura e pelo CNE, principalmente após a promulgação da Lei de Diretrizes e Bases da Educação Nacional, n. 9.394/96, de 20 de dezembro de 1996 (Brasil, 1996), momento que acarretou uma série de mudanças que colocaram no centro das reformas questões do currículo escolar, bem como os da formação de professores para a educação básica.

Os documentos consignados pelo MEC e CNE foram originados após vários debates que tiveram a representação dos segmentos da comunidade brasileira da educação. Esta estratégia foi utilizada a fim de contrapor as políticas anteriores, que consideravam os educadores como executores de determinações e programas elaborados pelo Estado.

As Diretrizes curriculares nacionais para a formação de professores da educação básica, regulamentada em fevereiro de 2002 pelo CNE, pode ser constituída como "numa dentre as muitas tecnologias de políticas promulgadas pelo governo brasileiro nas últimas duas décadas visando à melhoria da qualidade educacional pela realização de reformas curriculares" (Schneider, 2007, p. 14). Regulamentadas em forma de pareceres e resoluções, as DCN estabelecem princípios orientadores, diretrizes para a formação docente e critérios referentes à organização curricular, sem a explicitação de conteúdos.

Iremos apontar a ênfase dada à formação do professor, a partir da resolução CNE/CP 1, de 18 de fevereiro de 2002. No artigo primeiro está explicitado o significado das DCN instituídas, que "constituem-se de um conjunto de princípios, fundamentos e procedimentos a serem observados na organização institucional e curricular de cada estabelecimento de ensino" (Brasil, 2002, p. 1). Este conjunto se aplica a todas as modalidades da educação básica. Percebemos que as orientações desta resolução é uma referência para a normatização de políticas curriculares institucionais e também para a construção do projeto político-pedagógico de cursos de graduação.

Apesar das emendas e reformulações que ocorreram ao longo dos últimos cinco anos após a sua promulgação e também da publicação de diretrizes criadas especificamente para cada curso de licenciatura, essa resolução "tornou-se reguladora dos procedimentos concernentes à reforma e à organização curricular dos cursos de formação inicial de professores para atuação na educação básica" (Schneider, 2007, p. 15).

A perspectiva de mudança na formação docente vem sendo motivada pelo discurso que critica a configuração tradicional nos contextos formativos iniciais. Mediante os reformadores, os processos educativos vivenciados não abarcam as características da atualidade e, nessa direção, o artigo segundo versa sobre a organização curricular, no qual constam orientações consideradas essenciais à formação, no que se refere à atividade docente, entre as quais: o ensino com ênfase na aprendizagem discente, a acolhida e o trato da diversidade, a prática de atividades de ampliação ao repertório cultural, o aperfeiçoamento em práticas de investigação, a utilização das TDIC e de 
possibilidades metodológicas, estratégicas e materiais de apoio inovadores e o desenvolvimento de hábitos colaborativos e de trabalho em equipe.

A partir das orientações mencionadas no artigo segundo sinalizamos a importância de uma formação, de um modo de gestão voltados para o estudante, para a diversidade, a cultura, a pesquisa, a valorização do trabalho colaborativo e a integração tecnológica voltada a educação e da recriação de estratégias metodológicas que coloquem em pauta a necessidade de uma nova dinâmica inovadora curricular para os cursos de graduação e para a formação docente.

No artigo terceiro da resolução CNE/CP 1, de 18 de fevereiro de 2002, constam alguns princípios orientadores referentes à formação de professores direcionados a atuação em diferentes modalidades da educação básica, sendo que, no inciso primeiro, consta a competência como concepção nuclear na orientação do curso, a coerência entre a formação proporcionada e a prática que se espera do futuro professor estão apontadas no inciso segundo, considerando dois aspectos fundamentais expressos nas alíneas seguintes:

a) a simetria invertida, onde o preparo do professor, por ocorrer em lugar similar àquele em que vai atuar, demanda consistência entre o que faz na formação e o que dele se espera; b) a aprendizagem como processo de construção de conhecimentos, habilidades e valores em interação com a realidade e com os demais indivíduos, no qual são colocadas em uso capacidades pessoais; c) os conteúdos, como meio e suporte para a constituição das competências; d) a avaliação como parte integrante do processo de formação, que possibilita o diagnóstico de lacunas e a aferição dos resultados alcançados, consideradas as competências a serem constituídas e a identificação das mudanças de percurso eventualmente necessárias. (Brasil, 2002, p. 2)

$\mathrm{Na}$ reforma dos núcleos as concepções de currículo e ensino são demarcadas e são evidenciados aspectos referentes a definição de conteúdos e disciplinas, tornandose referência da nova perspectiva curricular voltadas a profissionalização do professor.

No inciso terceiro a categoria pesquisa aparece como foco nos processos de ensinar e aprender e especifica uma concepção de ensino que implica na disposição e a compreensão do processo da construção de conhecimentos, a fim de que estes possam ser mobilizados para a ação.

Em lugar de disciplinas e conteúdos, a referida resolução faz alusão, no artigo quarto, a um conjunto de competências necessárias inerentes à profissionalização dos educadores, que devem ser adotadas na proposta pedagógica, no currículo, no processo avaliativo, na organização institucional e nos processos de gestão.

Essas competências irão aparecer detalhadamente nas alíneas e nos parágrafos do artigo sexto referentes ao comprometimento com os valores da sociedade democrática; à compreensão do papel social da escola; ao domínio de conteúdos, sua repercussão em diferentes contextos e a articulação interdisciplinar; ao domínio do conhecimento pedagógico; ao conhecimento dos processos investigativos em prol do aperfeiçoamento da prática pedagógica; ao gerenciamento do próprio desenvolvimento profissional.

Ao projeto político pedagógico é dada a ênfase a partir do artigo quinto e este necessita levar em conta uma formação que contemple as competências objetivadas na 
educação básica, sendo que o desenvolvimento destas implica em uma formação que considere diferentes âmbitos do conhecimento profissional do professor; a seleção de conteúdos que devem se orientar por além daquilo que os professores irão ministrar nas diferentes etapas; estes conteúdos a serem abordados na educação básica precisam estabelecer relações com as didáticas específicas; e, por fim, a avaliação terá como finalidade a orientação do trabalho dos formadores, a autonomia dos futuros professores em relação ao seu processo de aprendizagem e a qualificação de profissionais com condições de iniciar a carreira. Além disso, no artigo quatorze é concedida flexibilidade e autonomia a cada instituição para construir um projeto políticopedagógico inovadores e únicos.

A aprendizagem mencionada é orientada pela ação-reflexão-ação no parágrafo único, que aponta como uma das estratégias de privilégio a resolução de situaçõesproblema. Ainda tratando-se das competências elencadas, a formação de professores é considerada na resolução como um processo autônomo. No caso de curso e licenciatura plena, numa estrutura com identidade própria, deve manter articulação com institutos, departamentos e cursos de áreas específicas; sustentar relações estreitas com a escola mediante o desenvolvimento de projetos compartilhados e na organização institucional será destinado um momento voltado a formação de formadores.

A prática é um dos elementos inerentes aos cursos de formação em nível superior e constam nos parágrafos do artigo décimo segundo que esta não pode ser restringida a um espaço isolado ao estágio e do currículo, sendo que necessita estar presente desde 0 início do curso e permear toda a formação docente. No parágrafo segundo do artigo 13 as tecnologias da informação e da comunicação são vistas como recursos enriquecedores da formação do professor:

$\S 2^{\circ}$ A presença da prática profissional na formação do professor, que não prescinde da observação e ação direta, poderá ser enriquecida com tecnologias da informação, incluídos o computador e o vídeo, narrativas orais e escritas de professores, produções de alunos, situações simuladoras e estudo de casos.

Fazendo menção a tese de Schneider (2007), estudos e pesquisas brasileiras demonstram haver uma relação desarmônica entre o projeto de sociedade sonhado pelos profissionais da educação e as perspectivas sustentadas pelas DCN direcionada aos educadores. Podemos citar o caso da teoria e da prática como um dos aspectos levantados para os cursos de formação de professores da educação básica, nos cursos formativos estão sendo predominante as perspectivas conservadoras, direcionadas a supervalorização de pressupostos teóricos em detrimento de situações práticas que poderiam ser mais exploradas e vivenciadas durante a graduação.

Nessa linha de pensamento, outras críticas são levantadas como a noção de competência como nuclear que manifestaria uma tendência a ressignificar a perspectiva curricular de instrumental-tecnicista, que foram difundidas no Brasil até o início de 1970, quando o "desenvolvimento de métodos de ensino e a determinação de objetivos educacionais em conformidade ao modelo produtivo dominante" (Schneider, 2007, p. 17) eram elementos considerados relevantes no preparo do professor.

Apesar de concordarmos que as incertezas que podem gerar as diretrizes à qualificação da formação de professores, acreditamos que a sua consolidação, mediante 
a construção de projetos político-pedagógicos, pode promover práticas curriculares inovadoras, possibilitando a reconstrução de trajetórias que não representem a adesão submissa às políticas curriculares oficiais, reinventando novos desenhos curriculares que levam a percursos formativos diferenciados do tradicional, fragilizadas e menos fragmentadas.

Passamos a analisar a resolução CNP/CP n. 1 de 15 de maio de 2006, que institui as Diretrizes curriculares nacionais para o curso de graduação em pedagogia, licenciatura, que propõem ao contexto formativo inicial para o exercício da docência. Em relação à atividade docente, esta versa sobre a participação na organização e gestão de sistemas e instituições de ensino, ou seja, não há uma dissonância entre a docência e os processos de gestão.

No artigo terceiro está explicitado que o futuro pedagogo deve trabalhar com um repertório de informações, a partir de habilidades desenvolvidas que sejam articuladas com os pressupostos teóricos e os saberes práticos, mediante fundamentação em princípios de "interdisciplinaridade, contextualização, democratização, pertinência e relevância social, ética e sensibilidade afetiva e estética" (Brasil, 2006, p. 1).

$\mathrm{Na}$ formação do pedagogo é considerado como primordial o conhecimento da escola, a pesquisa voltada para a área educacional e a participação na gestão de processos educativos e na organização e funcionamento de sistemas e instituições de ensino. São compreendidas como atividades docentes:

I - planejamento, execução, coordenação, acompanhamento e avaliação de tarefas próprias do setor da Educação; II - planejamento, execução, coordenação, acompanhamento e avaliação de projetos e experiências educativas não-escolares; III - produção e difusão de conhecimentos científico-tecnológico do campo educacional, em contextos escolares e não-escolares. (Brasil, 2006, p. 2)

No que se refere às aptidões do pedagogo egresso, baseadas nos dezesseis incisos do artigo quinto, destacamos apenas o inciso sétimo, que trata da importância de relacionar ao âmbito educacional as linguagens apresentadas nos meios de comunicação, demonstrando domínio das tecnologias da informação e comunicação adequadas ao desenvolvimento de aprendizagens significativas. No entanto, para que as tecnologias estejam incluídas nos processos de ensino e aprendizagem, é necessário que haja um preparo durante a formação inicial, pois a formação acadêmica do futuro pedagogo não reproduz uma dinâmica capaz de provocar o desenvolvimento da autonomia diante da cultura digital.

Nesse sentido, o professor necessita ter 0 conhecimento das técnicas computacionais para que possa integrar o computador em sua prática pedagógica. Atualmente entendemos que o educador necessita ampliar o seu conhecimento acerca do repertório tecnológico existente, pois as TDIC não estão reduzidas apenas a computadores, pois outras tecnologias, como aparelhos de última geração, perpassam as salas de aulas e são dominados pelos nativos digitais.

A partir do item número 11 percebemos que está sendo expresso de maneira implícita um modelo de gestão baseado no viés participativo. Logo, no item 12, a participação está mais evidente e destacamos que uma das atividades da gestão é contribuir com o processo de elaboração, execução e avaliação do projeto político 
pedagógico. A seguir, confirmamos no item 13, que a participação é uma dimensão enfatizada, o que revela uma determinada concepção de gestão:

Considera-se que o significado de gestão, [...], traz em si implícito o caráter participativo, assim como o traz a democracia. Em vista disso, as expressões "gestão participativa" e "democracia participativa" são, de certa forma, redundantes, tratando-se, no entanto, de uma redundância útil, no sentido de reforçar uma das dimensões mais importantes da gestão educacional democrática, sem a qual esta não se efetiva. (Brasil, 2006, p. 27)

Entendemos também que, em consonância com os itens 11, 12 e 13, a concepção de gestão permeia todos os segmentos do sistema, sendo este considerado como um todo, tanto em âmbito macro - gestão do sistema de ensino -, como no micro - gestão de escolas. Para que os processos de gestão ocorram é imprescindível a participação em nível macro e micro, pois é contemplada como um "processo inerente à gestão educacional" (Brasil, 2006, p. 21).

Conforme Lück (2010), esta participação concede aos sujeitos envolvidos o domínio de seu próprio trabalho, possibilitando que a autoria e a responsabilidade pelos resultados alcançados sejam assumidas de maneira autônoma: "Daí porque a participação competente é o caminho para a construção da autonomia" (Brasil, 2006, p. 23).

Em relação a participação voltada a construção, execução e avaliação do projeto político pedagógico, Luck (2010) defende que

a participação efetiva na escola pressupõe que os professores, coletivamente organizados, discutam e analisem a problemática pedagógica que vivenciam em interação com a organização escolar e que, a partir dessa análise, determinem caminhos para superar as dificuldades que julgarem mais carentes de atenção e assumam compromisso com a promoção de transformação nas práticas escolares. (Brasil, 2006, p. 33)

O engajamento representa o nível mais elevado da participação e sua prática implica no estar presente, sugerir ideias, opiniões, analisar interativamente as situações emergentes, tomar decisões compartilhadas acerca de questões que perpassam 0 cotidiano educacional. Nestas situações é exigida uma postura comprometida com o encaminhamento e com as ações necessárias e adequadas à efetivação das decisões.

As Diretrizes curriculares nacionais gerais para a educação básica têm por objetivos

I - sistematizar os princípios e as diretrizes gerais da Educação Básica contidos na Constituição, na Lei de Diretrizes e Bases da Educação Nacional (LDB) e demais dispositivos legais, traduzindo-os em orientações que contribuam para assegurar a formação básica comum nacional, tendo como foco os sujeitos que dão vida ao currículo e à escola; II - estimular a reflexão crítica e propositiva que deve subsidiar a formulação, a execução e a avaliação do projeto político-pedagógico da escola de Educação Básica; III - orientar os cursos de formação inicial e continuada de docentes e demais profissionais da Educação Básica, os sistemas educativos dos diferentes entes federados e as escolas que os integram, indistintamente da rede a que pertençam. (Brasil, 2010, p. 1) 
As categorias projeto político-pedagógico e gestão democrática ganham evidência no Título VII denominado Elementos constituitivos para a organização das diretrizes curriculares nacionais gerais para a educação básica, junto a outros elementos como regimento escolar, sistema de avaliação, organização escolar, o professor e o programa de formação docente.

No capítulo primeiro existe um maior detalhamento a respeito do projeto políticopedagógico que é considerado mais do que um documento, pois é um dos meios viabilizadores da escola democrática para todos e também de qualidade social. A formulação do PPP deve ser articulada com a identidade escolar e de seus sujeitos, junto aos planos nacional, estadual e municipal da educação, levando em conta o contexto e as necessidades locais apresentadas pela escola e seus estudantes.

O projeto político-pedagógico, definido no artigo 44 como uma "instância de construção coletiva que respeita os sujeitos das aprendizagens, entendidos como cidadãos com direitos à proteção e à participação social" (Brasil, 2010, p. 14), deve contemplar o diagnóstico da realidade dos sujeitos, a concepção sobre educação, o perfil dos sujeitos, o trabalho pedagógico, fundamentos da gestão democrática, compartilhada e participativa, programas de formação inicial e continuada dos profissionais da educação, entre outros aspectos contidos nesta Resolução.

A autonomia da instituição educacional é um elemento que aparece e fundamenta-se na busca da própria identidade, que se propaga na construção do projeto político-pedagógico e do regimento escolar. Freire (2014) considera a autonomia como um princípio pedagógico para educadores progressistas e é uma forma de libertação dos sujeitos das tendências neoliberais que vai se constituindo nas experiências de várias decisões que vão sendo tomadas de modo coletivo.

Decisões coletivas implicam na perspectiva da gestão democrática. Esta categoria e a organização escolar são contempladas no capítulo terceiro. Torna-se pressuposto da organização do trabalho pedagógico e da gestão da escola concebermos "a organização e a gestão das pessoas, do espaço, dos processos e procedimentos que viabilizam o trabalho expresso no projeto político-pedagógico e em planos da escola, em que se conformam as condições de trabalho definidas pelas instâncias colegiadas" (Brasil, 2010, p. 16). A gestão democrática torna-se obrigatória no ensino público, bem como também para todas as instituições de ensino, o que implica a tomada de decisões coletivas e a participação da comunidade na gestão.

Nessa direção, o exercício da gestão democrática deve promover nas instituições educativas um espaço das

diferenças e da pluralidade, inscrita na diversidade do processo tornado possível por meio de relações intersubjetivas, cuja meta é a de se fundamentar em princípio educativo emancipador, expresso na liberdade de aprender, ensinar, pesquisar e divulgar a cultura, o pensamento, a arte e o saber. (Brasil, 2010, p. 17)

A emancipação é uma categoria freiriana entendida como sinônimo de libertação, humanização em que os sujeitos são considerados "seres da busca e se sua vocação ontológica é humanizar-se, podem, cedo ou tarde, perceber a contradição em que a "educação bancária pretende mantê-los e engajar-se na luta por sua libertação" (Freire, 
1983, p. 70). Na perspectiva emancipatória, todos os sujeitos envolvidos tomam decisões, produzem conhecimentos e aprendem juntos, despertando-se para a sua própria vocação ontológica que consiste em ser sujeito da própria realidade.

A maneira de fazer gestão nos processos educativos não comporta mais o ato de tomadas de decisões individuais e a propagação de valores que condicionam a atender aos ditames do mercado, às necessidades da produção voltada para o lucro, no entanto, visa a preparação de profissionais comprometidos com um projeto de sociedade voltado para a construção integral, ética, estética, político e social dos sujeitos. Assim sendo, a gestão democrática promove a emancipação dos sujeitos envolvidos, na medida em que visa uma educação voltada para cidadania, superando a verticalização das relações e o autoritarismo no que se refere a organização curricular, conforme é detalhado no artigo 55.

Destacamos no inciso III do referido artigo a importância do diálogo acerca da própria práxis pedagógica. No capítulo IV da resolução, é abordado sobre $O$ professor e a formação inicial e continuada. É proposto que, no âmbito da formação inicial e continuada, as instituições formativas dos profissionais da educação incluam em seus currículos e programas o conhecimento da escola como uma organização complexa, cuja função é de promover a educação voltada para e na cidadania; a pesquisa de investigações referentes à área da educação; a participação na gestão de processos educativos e na organização e funcionamento tanto de sistemas quanto de instituições de ensino; a inserção da temática da gestão democrática, enfatizando a construção do PPP, a partir do trabalho baseado na coletividade, tornando responsáveis todos os que fazem parte da instituição educativa.

Constatamos, no artigo 57, a valorização do professor no entendimento de que valorizá-lo consiste em: "valorizar a escola, com qualidade gestorial, educativa, social, cultural, ética, estética, ambiental” (Brasil, 2010, p. 18). A valorização profissional também se associam à exigência de programas de formação inicial e continuada de docentes e não docentes, sendo que estes programas, atrelados a esta diretriz, devem prepará-los para o desempenho de suas atribuições que são: desenvolver um conjunto de habilidades cognitivas e, além disso, pesquisar, elaborar propostas e reconstruir conhecimento de modo coletivo, trabalhar em colaboração, compreender e utilizar os instrumentos produzidos ao longo da evolução tecnológica e desenvolver competências para integração com a comunidade.

Considerando essas atribuições, fica claro que a formação inicial não finda o desenvolvimento dos conhecimentos, saberes e habilidades mencionadas e, por isso, a importância da formação permanente que possibilite ao futuro professor a aquisição de conhecimentos peculiares da profissão docente, a fim de se tornarem seres mais capacitados a atender as especificidades da sociedade que se modificam constantemente, o que implica em uma atualização permanente.

Passamos a analisar o PPP do curso de licenciatura em Pedagogia da Universidade Federal de Santa Maria. O referido curso tem por objetivo geral formar professores/profissionais em nível superior para atuar na educação infantil e nos anos iniciais do ensino fundamental. Os licenciados saem capacitados para atuar nas diferentes modalidades de ensino, como também nas demais áreas nos quais sejam previstos conhecimentos de cunho pedagógico. 
O funcionamento deste curso ocorre no turno vespertino, semestralmente, com ingresso anual e matrícula por disciplinas. Abrange oito semestres e organiza-se em três núcleos que perpassam todos os semestres: Núcleo de Estudos Básicos, Núcleo de Aprofundamento e Diversificação de Estudos e Núcleo de Estudos Integradores, baseados em um viés curricular dinâmico-dialógico, sendo que o diálogo entre os semestres e as disciplinas é considerado um aspecto fundamental na constituição de cada período letivo.

As disciplinas do Núcleo de Estudos Básicos são recomendadas para cada semestre e tem caráter obrigatório, integrando o conhecimento do educando sobre a realidade em que está inserido, tendo em vista o trabalho pedagógico junto a sua área de atuação bem como a iniciação da pesquisa e do ensino. O Núcleo de Aprofundamento e Diversificação de Estudos caracteriza-se pela formação do professor/investigador, que ao inserir-se em espaços educativos informais e formais, busca a ação pedagógica pela proposta educativa com a finalidade da participação do pedagogo no âmbito em que atua; e o Núcleo de Estudos Integradores, representado pelos eixos articuladores, tem a finalidade de promover a articulação entre todas as disciplinas do semestre. São sistematizadas como Disciplinas Complementares de Graduação - DCG. Embora as Práticas Educativas - PED - são tidas como DCG, essa modalidade de oferta disciplinar é concebida pela coordenação do curso como obrigatória. A aprovação ou a reprovação dependerá da participação e presença dos estudantes nas atividades que são coordenadas por todos os professores que ministram a disciplina no semestre.

Para a inserção dos estudantes no campo de atuação profissional busca-se articular os pressupostos teóricos estudados na universidade às situações práticas que são emergentes no contexto da escola, por meio do estágio supervisionado. Este momento é vivenciado no oitavo semestre, $150 \mathrm{~h}$ de docência em cada um, com a finalidade de desenvolver práticas educativas reflexivas sobre o exercício de ser professor. Para realizar o estágio supervisionado a condição é ter concluído com aprovação total todas as disciplinas obrigatórias indicadas nos semestres anteriores.

$\mathrm{Na}$ matriz curricular verificamos apenas uma disciplina que contempla a integração das TDIC, intitulada Tecnologias da Informação e da Comunicação Aplicadas à Educação, de 60h, no terceiro semestre do curso. O seu objetivo geral é que estudante seja capaz de constituir uma visão crítica, teórica e prática do uso das tecnologias da informação e comunicação, considerando os diferentes papéis a serem assumidos por professores e alunos em uma sociedade pautada pelo conhecimento.

O fato do curso ofertar essa disciplina sinaliza a importância da integração das tecnologias como uma forma de mediação pedagógica nas práticas do futuro pedagogo, mas ocorre que essa disciplina encerra e não existe a continuidade no que se refere à aplicabilidade das TIC relacionadas às demais disciplinas do currículo.

No documento em evidência consta que o projeto está com consonância com as DCN no que se refere à carga horária mínima exigida, no entanto, não localizamos nenhum objetivo voltado para a formação tecnológica do educando de Pedagogia, aspecto mencionado nas diretrizes. A tecnologia perpassa minimamente objetivos específicos, não sendo contemplada como algo inerente a formação do futuro pedagogo do século 21. 


\section{Considerações finais}

Entendemos que a gestão implica em um processo que envolve um ou mais interlocutores, com os quais se dialoga em prol da busca de respostas para as situações emergentes. Atualmente os cenários educativos são permeados pelos desafios da cultura digital e carecem de uma formação apoiada na partilha de experiências que exploram, demonstram e analisam as possibilidades inovadoras da integração das TDIC no currículo dos cursos.

Ao realizarmos a análise do PPP do curso de licenciatura em Pedagogia diurno/UFSM, percebemos que há uma preocupação em promover uma aproximação da cultura digital no currículo, no entanto, ainda existem fragilidades que desencadeia o afastamento desta perspectiva, pois encontramos apenas uma disciplina, intitulada Tecnologias da Informação e da Comunicação Aplicadas à Educação, com 60h, que compõe o Núcleo de estudos básicos do currículo. O PPP do curso está em consonância com as DCN no que se refere à carga horária mínima exigida, contudo, não localizamos nenhum objetivo que contemple a formação para a fluência tecnológica do futuro professor.

Em relação às disciplinas complementares não encontramos, na listagem disponibilizada no site do curso de Pedagogia e no PPP, as que contemplem a integração das TDIC. No entanto, sabemos da existência de uma disciplina complementar de graduação, que não consta no site do referido curso, mas que é ofertada aos estudantes, como é o exemplo da disciplina Ensino-Aprendizagem em Ambientes Virtuais de EnsinoAprendizagem, de 30h.

No currículo do curso também não são especificadas todas as disciplinas complementares. Existe apenas a carga horária total que precisa ser cumprida nas DCG, pois não há como prever quais disciplinas serão ofertadas nos semestres.

Com relação às políticas públicas, mais precisamente às resoluções que foram analisadas, constatamos uma ênfase significativa dada à formação do professor, pois busca-se um perfil docente e discente comprometido com as transformações sociais. Estão explicitadas categorias como democrática, participativa, autonomia, que evidenciam um modelo de gestão almejado e, no que se refere à formação de professores, busca-se uma formação baseada na dimensão humana, entretanto, a dimensão tecnológica é abordada brevemente e de forma minimalista.

Da mesma forma, no PPP do curso percebemos que não está explícito um modelo de gestão. Encontram-se, de maneira implícita, algumas concepções pelas expressões democrática e participativa, o que implica em formas de gestão.

Assim sendo, o uso de tecnologias em cursos presenciais possibilita a dinamização das aulas, deixando-as mais vivas, atrativas e participativas e cooperando para 0 processo de ensino e aprendizagem à distância, virtual. É importante ressaltar que não se pode pensar no uso de uma TDIC de modo isolado, seja na educação presencial ou virtual, visto que o planejamento do processo de ensino e aprendizagem necessita ser contemplado em sua totalidade e em cada uma de suas dimensões.

Promover a utilização das tecnologias nas disciplinas do curso possibilitará ao futuro pedagogo a oportunidade de entrar em contato com novas informações, pesquisas e produções científicas, a fim de promover a construção do conhecimento a partir da integração de recursos tecnológicos. Assim sendo, as técnicas não irão se justificar por si 
próprias, mas pelos objetivos que se pretenda que elas alcancem - objetivos de ensino e aprendizagem.

Evidenciamos que, na cultura digital, há necessidade de variar estratégias, tanto para motivar os estudantes, quanto para atender os diferentes ritmos, tempos, espaços e formas, pois existe uma heterogeneidade no que se refere à maneira de ensinar e aprender.

Concluímos que o PPP somente desempenhará a função de instrumento de organização pedagógica das instituições educativas se for construído coletivamente com o objetivo de potencializar os processos de ensino e aprendizagem na cultura digital. A participação da comunidade nas formas de gestar é imprescindível neste processo, pois implica na construção de novas possibilidades de construção do projeto o que pode desencadear a transformação da realidade frente os desafios propostos pela cultura digital.

\section{Referências}

BARRETO, Raquel Goulart. Novas tecnologias na educação presencial e a distância II. In: BARBOSA, Raquel Lazzari Leite (org.). Formação de educadores: desafios e perspectivas. São Paulo: Unesp, 2003, p. 109-118.

BRASIL. Lei de diretrizes e bases da educação nacional n. 9.394. Diário Oficial da União - DOU. Brasília: 21 dez. 1996. Disponível em: <http://www.planalto.gov.br/ccivil 03/leis/ L9394.htm>. Acesso em 22 jul. 2012.

BRASIL. Ministério da Educação, Conselho Nacional de Educação. Conselho Pleno. Resolução CNE/CP n. 1. Diretrizes curriculares nacionais para a formação de professores da educação básica, em nível superior, curso de licenciatura, de graduação plena. Diário Oficial da União - DOU. Brasília, 18 de fevereiro de 2002. Disponível em:<http://portal.mec.gov.br/cne/arquivos/pdf/rcp01_02.pdf>. Acesso em 9 jun. 2014.

BRASIL. Resolução CNE/CP n. 1. Diretrizes curriculares nacionais para o curso de graduação em Pedagogia, licenciatura. Diário Oficial da União - DOU. Brasília, 15 de maio de 2006. Disponível em: <http://portal.mec.gov.br/cne/arquivos/pdf/rcp01_06.pdf>. Acesso em 9 jun. 2014.

BRASIL. Resolução n. 4. Diretrizes curriculares nacionais erais para a educação básica. Diário Oficial da União - DOU. Brasília, 13 de julho de 2010. Disponível em: <http://portal.mec.gov.br/dmdocuments/rceb004_10.pdf>. Acesso em 9 jun. 2014.

CUNHA, Marcus Vinicius da. Jonh Dewey: uma filosofia para educadores em sala de aula. Petrópolis: Vozes, 2002.

FERREIRA, Naura Syria Carapeto (org.). Formação continuada e gestão da educação. In: FERREIRA, Naura Syria Carapeto. Formação continuada e gestão da educação no contexto da cultura globalizada. São Paulo: Cortez, 2007, p. 17-42.

FERREIRA, Naura Syria Carapeto (org.). Formação continuada e gestão da educação. In: BARROSO, João. A formação dos professores e a mudança organizacional das escolas. São Paulo: Cortez, 2007, p. 117-143.

FERREIRA, Naura Syria Carapeto; BITTENCOURT, Agueda Bernadete (orgs.). Formação humana e gestão da educação: a arte de pensar ameaçada. In: FERREIRA, Naura Syria Carapeto. Formação humana, práxis e gestão do conhecimento. São Paulo: Cortez, 2008, p. 51-82. 
FREIRE, Paulo. Pedagogia do oprimido. Rio de Janeiro: Paz e Terra, 1983.

FREIRE, Paulo. Pedagogia da autonomia: saberes necessários à prática educativa. Rio de Janeiro: Paz e Terra, 2014.

FREITAS, Maria Teresa. Janelas sobre a utopia: computador e internet a partir do olhar da abordagem histórico-cultural. In: REUNIÃO ANUAL DA ASSOCIAÇÃO NACIONAL DE PÓS-GRADUAÇÃO E PESQUISA EM EDUCAÇÃO, 32, 2009, Caxambu. Anais... Caxambu: Anped, 2009, p. 1-14.

IMBERNÓN, Francisco. Formação docente e profissional: formar-se para a mudança e a incerteza. São Paulo: Cortez, 2010.

LÉVY, Pierre. Cibercultura. São Paulo: 34, 1999.

LÜCK, Heloísa. A gestão participativa na escola. Petrópolis, Vozes: 2010.

MORAN, José Manuel; MASETTO, Marcos; BEHRENS, Marilda Aparecida. Novas tecnologias e mediação pedagógica. In: MORAN, José Manuel. Ensino e aprendizagem inovadores com tecnologias audiovisuais e telemáticas. Campinas: Papirus, 2000. p. 1165.

PRENSKY, Marc. Nativos digitais, imigrantes digitais. On the Horizon, v. 9, n. 5, 2001, p. 1-6. Disponível em: <https://docs.google.com/document/d/1XXFbstvPZIT6Bibw03JSsMmd DknwjNcTYm7j1a0noxY/edit>. Acesso em 5 maio 2013.

PRENSKY, Marc. O papel da tecnologia no ensino e na sala de aula. Conjectura, v.15, n. 2, p. 201-204, 2010. Disponível em <http://www.ucs.br/etc/revistas/index.php/conjectura/ article/viewFile/335/289 >. Acesso em 4 jun. 2013.

SCHNEIDER, Marilda Pasqual. Diretrizes curriculares nacionais para a formação de professores da educação básica: das determinações legais às práticas institucionalizadas. 2007. 199f. Tese (doutorado em Educação). Universidade Federal de Santa Catarina.

VALENTE, José Armando (org.). Computadores e conhecimento: repensando a educação. Campinas: Unicamp, 1993.

Edenise do Amaral Favarin é licenciada em Pedagogia pela Universidade Federal de Santa Maria, especialista em Gestão Educacional e estudante do curso de mestrado em Educação na mesma instituição.

Endereço: Avenida Evandro Behr, 5948 - 97110-630 - Santa Maria - RS - Brasil.

E-mail: edenisefavarin@gmail.com.

Adriana Moreira da Rocha é professora na Universidade Federal de Santa Maria e coordenadora do Programa de Pós-Graduação em Educação na mesma instituição.

Endereço: Avenida Roraima, 1000 - 97105-900 - Santa Maria - RS - Brasil.

E-mail: adrianaufsm@gmail.com.

Recebido em 15 de dezembro de 2014.

Aceito em 22 de maio de 2015. 